\title{
What we know about COVID-19 and its treatment
}

\author{
Zatiye Ayça ÇEVIKKELLİ YAKUT 1,2 (D), Sinem ŞAKARCAN 3 (D), Göksel ŞENER 1 * (D) \\ 1 Department of Pharmacology, Faculty of Pharmacy, Marmara University, Haydarpaşa 34668 İstanbul, Turkey. \\ 2 Department of Pharmacognosy, Faculty of Pharmacy, Trakya University, 22030 Edirne, Turkey. \\ 3 St. Christopher's Hospital for Children, Department of Pediatrics, Philadelphia, USA \\ * Corresponding Author. E-mail: gsener@marmara.edu.tr (G.Ş.); Tel. 00-90-216-414-29-62.
}

Received: 21 July 2020 / Revised: 22 August 2020/ Accepted: 25 August 2020

\begin{abstract}
Severe acute respiratory syndrome corona virus 2 (SARS-CoV-2) which is the human coronavirus and a member of the Coronaviridae family leads to fatal pneumonia cases. Severe acute respiratory syndrome corona virus 2 attaches to the cells in the human body through binding to the angiotensin converting enzyme 2 (ACE2) receptor with the spike (S) protein. Firstly, SARS-CoV-2 arised in China in late 2019 and was reported to the World Health Organization (WHO). The World Health Organization named the disease caused by this virus as corona virus disease (COVID)-19. SARS-CoV-2 which has human-to-human transmission through droplets, direct contact and aerosol routes have affected more than 10 million people and caused more than 500 thousand deaths. Clinical symptoms of COVID19 are fever, dry cough, sore throat, respiratory distress, lung damage, and diarrhea. In severe cases, mechanical ventilation is required and multiple organ damage is encountered. COVID-19 is diagnosed with real-time polymerase chain reaction (PCR) technique which is applied to saliva and swab samples taken from the nose or nasal cavity. Lung damage is detected by computerized tomography (CT). COVID-19 develops more severely in patients with comorbidities such as hypertension, diabetes and cancer. While vaccine and drug development studies are continuing all over the world, available antiviral drugs such as umifenovir, remdesivir, favipiravir are also tested against SARS$\mathrm{CoV}-2$. Moreover, the plasma donated from the recovered patients are tested for COVID-19 treatment. Additionally, treating the inflammatory conditions developing due to COVID-19 and applying antimicrobial drugs against coinfections are among the current approaches.
\end{abstract}

KEYWORDS: SARS-CoV-2; COVID-19; COVID-19 comorbidities; COVID-19 treatment.

\section{INTRODUCTION}

Until today, three different coronaviruses have caused fatal pneumonia cases. At first in 2002, severe acute respiratory syndrome coronavirus (SARS-CoV) appeared in Guangdong province of China; it infected 8,096 people and caused 774 deaths and spread to 5 continents [1, 2]. In 2012, the Middle East respiratory syndrome coronavirus (MERS-CoV) occurred in the Arabian Peninsula; it infected 2,494 people and led to 858 deaths [3]. Lastly, previously unknown coronavirus was discovered in Wuhan city in Hubei province of China and it was reported to the World Health Organization (WHO) on December 31, 2019. This atypical pneumonia was isolated by the Chinese authorities as new coronavirus (2019-nCoV) on January 7, 2020. On January 12, 2020, the genetic sequence of the new coronavirus was shared with other countries for the development of specific diagnostic kits. On February 11, 2020, WHO entitled this viral disease as "coronavirus disease 2019" (COVID-19) and declared COVID-19 as a pandemic on March 11, 2019 [4]. As of July 1, 2020, COVID-19 has been diagnosed in more than 10 million people and caused more than 500 thousand deaths worldwide [5]. The International Committee on Taxonomy of Viruses entitled this virus as SARS-CoV-2 because of its similarity to the SARS symptoms [6]. Although COVID-19 has a milder clinical disorder compared to SARS and MERS in the great majority of patients, the transmission rate of SARS-CoV-2 infection from person to person is significantly higher [7]. In addition, COVID-19 creates a more dangerous clinical picture in the presence of comorbidity such as hypertension and diabetes [8].

Coronavirus is a member of the Coronaviridae family, its subfamily is Coronavirinae. Coronavirinae consists of 4 genera as Alpha-coronavirus, Beta-coronavirus, Gamma-coronavirus and Delta-coronavirus. SARS-CoV-2 which belongs to Beta-coronavirus genus is an enveloped virus containing a single-stranded RNA genome. In genomic analysis; $79 \%$ similarity between SARS-CoV-2 and SARS-CoV has been determined [6]. Similar to SARS-CoV; spike protein (S) of SARS-CoV-2 plays an important role in host selectivity and

\footnotetext{
How to cite this article: Çevikelli Yakut ZA, Şakarcan S, Şener G. What we know about COVID 19 and its treatment. J Res Pharm. 2020; 24(5):
} 602-616. 
cellular adherence [9]. After the surface unit of S protein binds to the angiotensin converting enzyme 2 (ACE2) receptor in the host, it undergoes proteolytic cleavage by the transmembrane serine protease (TMPRSS) 2 in the host cell cytosol. S2 released by cleavage of the S protein from the S1 / S2 domain allows fusion of viral and cellular membranes [10]. Angiotensin converting enzyme 2 receptor, integral membrane glycoprotein, is expressed in the bronchi, lung parenchyma, heart, endothelium, kidneys, duodenum and small intestine [11]. Transmembrane serine protease 2 expression has been detected in airway epithelial cells, GI tract, cardiomyocytes, blood vessels and kidneys [12].

\section{COVID-19 GENERAL FEATURES}

\subsection{Modes of transmission}

Since the first COVID-19 patients had a history of direct contact with local Chinese seafood and wild animal market, the main route of transmission was reported as zoonotic exposure [10]. Bats are known as reservoir hosts of SARS-CoV-2. On the other hand, for zoonotic transport, the intermediate host of SARS-CoV2 has not been detected accurately yet [13]. In some studies, pangolin is suggested to be a mammalian intermediate host. Since the SARS-CoV-2 spike protein is almost identical to the spike protein of a virus isolated from pangolin, it was thought that pangolins could have provided the partial spike gene to SARSCoV-2 to infect the humans [6]. Overexpression of ACE2 on the luminal surface of intestinal epithelial cells supports that the first entry of SARS-CoV-2 into the human body might have been through nutrition [14]. Afterwards, transmission from person to person was detected. The virus is transmitted mainly through droplets, direct contact and aerosols. Droplet transmission can be defined as inhalation of respiratory droplets through mouth or nose, when an infected person coughs or sneezes. People can also be infected by touching a virus-contaminated surface or object and then touching their mouth, nose, or eyes [8].

There have not been reports of pets infected with SARS-CoV-2 yet. COVID-19 patients are recommended to limit contact with their animals until more information about the virus is learned [15]. Shi et al. (2020) reported that cats and ferrets could be experimentally infected with SARS-CoV-2, but that dogs, pigs, chickens and ducks were not susceptible to SARS-CoV-2. According to this study, cats can spread SARS-CoV2 by inhalation and transmit it to other cats [16].

\subsection{Incubation period}

The World Health Organization reports that COVID-19 symptoms develop on average 5-6 days after exposure, but this period may be extended to 14 days. For this reason, 14 days which is expressed as the quarantine period is the internationally applied time to monitor and restrict the movement of healthy individuals in contact with the patient with COVID-19 [17].

\subsection{Demographic and clinical features}

Although all age groups are affected by COVID-19, the cases in the older age group are detected as more severe [8]. While mild fever, sore throat, nausea, vomiting, and diarrhea are being encountered in the mild cases, fever, respiratory symptoms such as dry cough and shortness of breath and lung damage can accompany in the moderate cases. In the severe cases, dyspnea, tachypnea, decreased blood oxygen saturation, and pulmonary infiltrates are observed. Critical cases occur 7 days after the first onset of symptoms. Acute respiratory distress syndrome requires mechanical ventilation, and in these conditions multiple organ failure, metabolic acidosis and hypercoagulation are generally observed [6]. In addition, neutrophil count, inflammatory markers, blood urea and creatinine levels are usually high, and lymphocyte counts are generally decreased [8]. Chest computerized tomography (CT) determines the ground glass opacifications which are frequently bilateral with peripheral distribution and involve the lower lobes [18].

The lung is the most susceptible organ to SARS-CoV-2 due to its large surface area and high ACE2 expression. Alveolar epithelial type 2 cells facilitate the coronaviral replication in the lungs by expressing the genes involved in the viral life cycle alongside of the ACE2 expression [14, 19]. On the other hand, the tissue distribution of ACE2 in the organs other than the lung causes multiple organ damage [12].

\subsubsection{Effects of SARS-CoV-2 on central nervous system}

In current studies; neurological signs and symptoms such as headache, confusion, dizziness, myalgia, fatigue, and high intracranial pressure have been detected in some COVID-19 patients [20]. SARS-CoV-2 infection can lead to various neurological diseases such as viral encephalitis, meningoencephalitis, ischemic stroke and hemorrhagic stroke [21]. Human coronavirus invasion into central nervous system (CNS) occurs 
soon after the infection. The virus enters the CNS and infects the neurons. This was confirmed during the 20022003 SARS-CoV epidemia. Virus particles were detected in the brain tissues of SARS-CoV infected humans with the autopsy [20]. In a recent COVID-19 case study, meningoencephalitis occurred without the respiratory distress. Clinical progression developed rapidly with disorientation and hallucinations [22].

Human coronavirus enters the CNS from the blood and peripheral organs and distributes to the brain. Moreover, it can enter to the brain with neuronal dispersion; first it infects peripheral neurons, then infects the neurons in CNS by using host cell layout. Presence of smell and taste disorders in some COVID-19 cases indicates that SARS-CoV-2 can infect the olfactory system and enter the CNS using the olfactory pathway [20]. SARS-CoV-2 can damage the endothelial integrity of the blood brain barrier (BBB) through binding to ACE2 receptos in the neurons and glial cells of the brain. Increased cytokines and chemokines in viral infections also damage the BBB that causes influx of leukocytes into the brain; therefore, seizures and encephalopathy occur. Moreover, SARS-CoV-2 infection in brain cells can play a role in stroke and ischemia by reducing the ACE2 expression. Another factor that causes stroke in COVID-19 patients is venous and arterial thromboembolism. SARS-CoV-2 infection increases the blood thrombin levels and activation of coagulation factors and decreases anticoagulant levels by activating proinflammatory cytokines [23]. Another pathway causing CNS damage in SARS-CoV-2 infection is that antibodies produced against SARS-CoV-2 generate cerebral edema and autoimmune encephalitis by attacking the antigens in cerebral vessels or neurons [21].

\subsubsection{Cytokine storm}

Cytokines play an important role in viral infections. Fast and well-coordinated innate immune response is the first line of defense to a viral infection. However irregular and excessive immune response can damage the human body. Especially in severe cases caused by coronavirus, where proinflammatory responses play an important role. Rapid viral replication and strong proinflammatory cytokine / chemokine response trigger the apoptosis in lung epithelium and endothelial cells. Therefore, the epithelial cell barriers of the pulmonary microvessels and alveoli are damaged. Vascular leakage and alveolar edema occur that results in hypoxia [24].

In COVID-19 patients, elevated expressions of interleukin (IL)- $1 \beta$, interferon (IFN)- $\gamma$ and monocyte chemoattractan protein 1 (MCP-1) were detected [24]. Serum IL-2 receptor and IL-6 levels have been reported to correlate with severity of disease in COVID-19 patients [25]. Moreover, in different studies, as compared with COVID-19 patients in general services, the patients in the intensive care unit had higher serum levels of granulocyte colony stimulating factor (G-CSF), IFN- $\gamma$ induced protein (IP)-10, MCP-1, macrophage inflammatory protein (MIP)-1a, and tumor necrosis factor (TNF)- $a$. According to these studies; the cytokine storm positively correlates with the severity of the disease. Cytokine storm also plays a role in the other organ failures alongside lung damage [24].

\subsubsection{COVID-19 in pregnancy}

Miscarriage, intrauterine growth restriction and preterm labor can be listed as the fetal complications of COVID-19. Since COVID-19 causes fever, hyperthermic fetal neuron damage can occur [26].

The vertical transmission risk of SARS-CoV-2 is theoretically possible since the placenta expresses the ACE2 receptor. In 2 newborns from mothers infected with COVID-19, shortly after the birth, COVID-19 was detected. However, in 46 other newborns from COVID-19 infected mothers, the vertical transmission has not been confirmed. In these patients, any viral isolates were not detected in the amniotic fluid, cord blood, breast milk and neonatal throat swabs. Since COVID-19 occurs in the third trimester in the vast majority of these pregnancies, the consequences when the infection develops in the early stages of pregnancy are unknown. The emergence of COVID-19 as a mild respiratory disease in the pediatric population is reassuring [26].

Since there is no evidence of vertical transmission; vaginal delivery is not contraindicated in COVID-19 patients. In the emergent delivery of critical patients, cesarean delivery is appropriate. In COVID-19 patients, delivery should be carried out using full personal protective equipment (PPE) and in rooms with negative pressure ventilation [26].

Breastfeeding is not contraindicated, since SARS-CoV-2 has not been detected in the breast milk yet. But in order to prevent the transmission through the droplet, the mother with COVID-19 should wear a mask while breastfeeding. The presence of antibodies in breast milk depends on when the maternal infection occurred during pregnancy. In addition, high doses of corticosteroids can suppress the maternal antibody response [26].

N95 masks are recommended to healthcare professionals who are exposed to potential or diagnosed COVID-19 patients. On the other hand, since these masks limit the air flow, they can affect maternal cardiorespiratory function and limits the fetal oxygenation. In the controlled clinical studies; wearing an N95 
mask with 1 hour physical activity in the 2nd and 3rd trimester of pregnancy reduced the breathing volume and ventilation, and increased carbon dioxide production due to labored breathing. For this reason, pregnant healthcare workers with growth-restricted fetuses should be warned to be careful against the use N95 masks. Moreover, they are not recommended to be on the front lines in the COVID-19 outbreak. In necessary situations, powered air-purifying respirators (PAPR) with high efficiency particulate air (HEPA) filters is a reasonable alternative due to less airway resistance [26].

\section{DIAGNOSIS}

COVID-19 is diagnosed with real time polimerase chain reaction (RT-PCR) technique applied to swab or saliva samples obtained from the respiratory regions such as nasopharynx and oropharynx [27]. In addition with serological tests applied to the blood samples, the presence of virus-specific antibodies is investigated. For this purpose enzyme linked immuno-sorbent assay (ELISA) and immunochromatographic methods are performed [6]. In earlier stage of disease, clinical findings are not present. Clinical signs and symptoms start with fever and dry cough [27].

Chest radiography and CT of infected patients demonstrate pulmonary involvement. Findings differ depending on the stage of the disease, age of the patient, and immune status. On $\mathrm{CT}$, ground glass opacifications and thickening of the interlobular septa can be observed [27]. Lung lesions are more common in patients over the age of 50 compared to younger patients. Clarity of radiographic examination is not as good as CT imaging that reveals the ground glass opacities [28].

\section{COVID-19 COMORBIDITIES}

It has been determined that the most severe COVID-19 patients are generally of advanced age and / or have underlying comorbidities such as hypertension, diabetes mellitus (DM), chronic lung and kidney diseases or cancer [8].

\subsection{Hypertension and COVID-19}

Cases of COVID-19 are encountered more frequently and more severely in the hypertensive patients. According to a proposed hypothesis; renin angiotensin aldosteron system overactivation leads to lung injury related to COVID-19 through triggering the inflammatory response and cytokine storm, stimulating the $\mathrm{NADH} / \mathrm{NADPH}$ oxidase system, the cellular contraction and vasocontraction [29].

\subsubsection{Hypertension treatment and COVID-19}

Angiotensin converting enzyme inhibitors (ACEIs) and angiotensin receptor blockers (ARBs) that are the renin-angiotensin system (RAS) inhibitor agents are used as the first-line therapy for the majority of hypertensive patients [29]. After ACE2 has been identified as the SARS-CoV-2 receptor, the idea that treatment with ACEIs and ARBs could be harmful to COVID-19 patients has spread rapidly. This hypothesis caused confusion in the patients who are under treatment with these drugs [30]. Angiotensin converting enzyme inhibitors reduce the angiotensin 2 levels that upregulates ACE2 receptor via negative feedback. Thereby ACE2 interacts more easily with reduced levels of angiotensin 2 substrate. Moreover, ARBs elevate the ACE2 levels and angiotensin 2 that cannot bind to its receptor is converted easily to angiotensin 1-7 [31]. It has been suggested that ACE2 receptor upregulation increases the susceptibility to COVID-19 by increasing SARS-CoV2 binding sites [32]. However, the evidence for ACE2 upregulation is limited to high doses of ARBs and ACEIs in animal studies and no clinical data is available [33].

In other respects, SARS-CoV infection reduces the ACE2 expression and dominates the RAS cascade. Elevation of ACE2 levels can alleviate increased vascular permeability, lung edema and neutrophil accumulation by balancing the ACE function [29]. For instance, it has been determined in the mice that loss of ACE2 generates resistance to SARS-CoV infection but exacerbates the pulmonary damage [29, 34-35]. Therefore, contrary to fear; some researchers suggested that ACEI or ARB therapy may be beneficial to prevent COVID-19 [32]. In the study of Kuba et al. with mice; in the acute lung injury triggered by acid aspiration, losartan reduced lung damage and pulmonary edema compared to placebo [34]. According to retrospective analysis, death and endotracheal intubation rates were decreased with ACEIs in the patients with viral pneumonia [36]. According to the presented reports; increased expression of ACE2 in the cell membrane can elevate the soluble ACE2 levels in the blood, most of the SARS-CoV-2 may bind to soluble ACE2, and interaction of SARS-CoV-2 with the membrane-bound receptor can be prevented. Thus, viral entry into the cell can be alleviated [37]. 
In the light of this information; treatment should not be discontinued in patients taking RAS inhibitor drugs for cardiovascular disease [33]. Europian Society of Hypertension, Europian Society of Cardiology, American Heart Association/Ammerican College of Cardiology, Heart Failure Society of America reported that ACEIs and ARBs used for comorbidities should be continued [38-40].

\subsection{Diabetes Mellitus and COVID-19}

In patients with diabetes, phagocytosis performed by neutrophils, macrophages and monocytes, neutrophil chemotaxis, bactericidal activity and innate cell- mediated immunity is damaged. Therefore, in diabetic patients diagnosed with COVID-19, a complicated clinical picture can occur as a result of secondary bacterial infection [41].

Hyperglycemia and insulin resistance elevate the synthesis of glycosylation end products and proinflammatory cytokines. Oxidative stress and adhesion molecule production are also triggered. These inflammatory processes increase the tendency to infection [8]. In the in vitro studies, in the pulmonary epithelial cells exposed to high concentration of glucose, elevated influenza viral infection and replication were determined $[8,42]$.

Increased ACE2 expression has been detected in the renal cortex, liver and pancreas of diabetic mice $[43,44]$. In addition, type 1 membrane-bound protease furin expression, which plays a role in the entry of coronaviruses into the cell, increases in diabetes [45].

In the report of 72,314 COVID-19 cases published by the China Center for Disease Control and Prevention; increased mortality with diabetes was determined [46]. In another study in China; it has been reported that 173 of 1099 COVID-19 cases were severe and 16\% of these severe cases had severe diabetes and $5.7 \%$ of the remainder had mild diabetes [47].

\subsubsection{Hyperglycemia and COVID-19}

SARS-CoV infection has been reported to cause transient hyperglycemia in patients without diabetes history. Transient hyperglycemia was suggested to be triggered by inflammation of islet cells of the pancreas [48].

In diabetic patients, SARS-CoV-2 infection increases the release of hormones such as glucocorticoids and catecholamines that elevate the blood glucose levels. Pancreatic damage, with elevated plasma amylase and lipase levels, was determined at a rate of 9/52 in hospitalized SARS-CoV-2 patients in China. Moreover, a slight increase in plasma glucose levels was detected in 6/9 of these patients [49]. Presence of ACE2 expression in exocrine and endocrine pancreas supports that SARS-CoV-2 causes pancreatic damage [50]. It has been suggested that SARS-CoV-2 causes hyperglycemia by infecting the pancreas. Therefore, especially the patients with poor glycemic control, hyperglycemia is aggravated [48]. In addition, glucocorticoid treatment in COVID-19 can cause the hyperglycemia [51].

According to the retrospective study report in Wuhan; hypoglycemia developed in $10 \%$ of the cases with coexistence of type 2 DM and COVID-19 [52]. Hypoglycemia activates the proinflammatory monocytes, increases platelet reactivity and cardiovascular mortality in diabetic patients. Consequently, caution should be exercised for the risk of both hyperglycemia and hypoglycemia following the inflammatory and immune response in COVID-19 cases, especially in the diabetic patients [8].

\section{COVID-19 TREATMENT}

Specific antiviral treatment against COVID-19 is not yet available. Therefore, existing drugs used in different indications are being tried [6]. Electrolyte, water and acid-base levels of patients are regulated. Myocardium and liver enzyme levels, bilirubin, blood urea nitrogen, creatinine, CRP levels and coagulation functions are checked to monitor organ functions and chest imaging is performed. In necessary cases, oxygen therapy, non-invasive and invasive mechanical ventilation are applied. Oxygen therapy is used as the first step in patients with respiratory distress, shock and hypoxemia [27].

The most effective way to fight against the corona virus infection is to develop immunity by developing vaccines. But it takes at least 12-18 months to develop a vaccine. For a new antiviral drug specific for SARS$\mathrm{CoV}-2$, it also takes time from the research and development phase to become available for use. For this reason, while the vaccine and drug research and development studies are continuing, the drugs used for viruses which have a similar genome with SARS-CoV-2 are tested against SARS-CoV-2 [53]. 
Potential ACE2-mediated approaches to COVID - 19 treatment can be listed as follows [14]:

a. Spike protein-based vaccine: $\mathrm{S} 1$ subunit based vaccine development studies rely on $\mathrm{ACE} 2$ as the receptor of SARS-CoV-2. The cell line that facilitates the viral replication in the presence of ACE2 can be effective in large-scale vaccine production.

b. Inhibition of transmembrane protease serin 2 (TMPRSS2) activity: This approach targets to inhibit the step that is necessary for viral spread. Camostat mesilate which is a clinically approved TMPRSS2 inhibitor abolished SARS-CoV-2 infection in lung cell line. It is seen as an option for COVID-19 therapy [10].

c. Angiotensin converting enzyme 2 receptor blockage: This approach targets to prevent interactions between ACE2 and SARS-CoV-2.

d. Excessive soluble ACE2 form: Excessive ACE2 can competitively bind to SARS-CoV-2 and can neutralize the virus and can protect the cellular ACE2 activity. It is expected that the soluble form of ACE2 can slow down virus entry into cells and protect the lungs by regulating RAS negatively [35, 54].

\subsection{Recombinant ACE2}

Angiotensin converting enzyme 2 has 2 different forms, one in the membrane and the other in circulation. Angiotensin converting enzyme 2 in the membrane has a structural transmembrane area that immobilizes its extracellular space to the plasma membrane. The extracellular domain acts as a receptor for the SARS-CoV and SARS-CoV-2 S protein. The soluble form of ACE2 has no connection with the membrane and it is present in small amounts in the blood. It has been suggested that this soluble form prevents binding of SARS-CoV and other coronaviruses to ACE2 surface in the membrane. Supportively in the in vitro research; SARS-CoV replication in the monkey kidney cell line was blocked by the soluble form ACE2 [55]. In another in vitro study; ACE2 coupled with immunoglobulin Fc fragment neutralized SARS-CoV-2 [56]. It is expected that soluble recombinant human ACE2 protein is effective in the treatment of coronavirus-induced infection [55].

In the previous studies, it was observed that recombinant human ACE2 is safe in healthy volunteers and the patients with acute respiratory distress [14].

According to the hypothesis; SARS-CoV-2 binds to soluble recombinant ACE2 which is abundant in the blood. Therefore ACE2 receptors in the lungs become free and they can demonstrate their tissue protective effects [30].

Angiotensin converting enzyme 2 elevates angiotensin 1-7 levels, alongside of decreasing the angiotensin 2 levels. Angiotensin 1-7 which is a member of RAS defined in year 2000 is synthesized from two separate pathways (Figure 1). Angiotensin 1-7 can be created directly by ACE2 with cleavage of angiotensin 2 or ACE2 creates angiotensin 1-9 by separating 1 amino acid from angiotensin 1 . Angiotensin 1-9 is cleaved to angiotensin 1-7 by ACE [57].

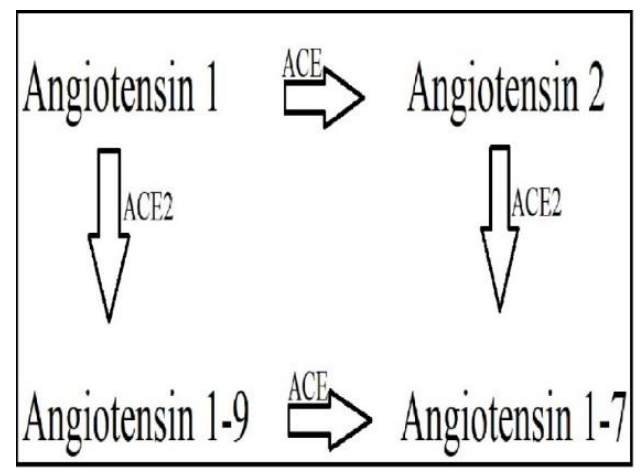

Figure 1. Angiotensin 1-7 synthesis. ACE: Angiotensin converting enzyme, ACE2: Angiotensin converting enzyme 2.

Angiotensin 1-7 demonstrates the opposite effects to proinflammatory, vasoconstrictor, proxidant, profibrotic and proproliferative effects of angiotensin 2 via $G$ protein coupled Mas receptor $[58,59]$. Thereby angiotensin 1-7 protects against fibrosis and inflammation in the lungs. Angiotensin 1-7 inhibits alveolar cell apoptosis, repairs barrier functions of endothelial cells, reduces edema, and restricts the synthesis of proinflammatory cytokines [59]. 


\subsection{Transmembrane serine protease 2 inhibitors}

Transmembrane serine protease 2 which provides the fusion of viral and cellular membranes by proteolytic cleavage of SARS-CoV-2 S protein, causes viral entry into cells [11]. Transmembrane serine protease 2 inhibitors camostat mesylate and naphamostat mesylate used in the treatment of acute pancreatitis are being investigated with clinical trials for the treatment of COVID-19 in Japan [33].

\subsection{Chloroquine and hydroxychloroquine}

Chloroquine and hydroxychloroquine, which have been used for many years in malaria and chronic inflammatory diseases such as rheumatoid arthritis and systemic lupus erythematosus have antiviral activity with various mechanisms. They are used for prophylaxis against COVID-19 in many countries [60, 61]. In an in vitro study; chloroquine inhibited SARS-CoV-2. In addition to its immunoregulatory and anti-inflammatory effects, it has been reported to increase endosomal $\mathrm{pH}$ and prevent SARS-CoV cellular receptor glycosylation, thereby preventing the viral infection [62]. According to computer simulations; it is estimated that hydroxychloroquine and chloroquine bind to the UDP-N-acetylglucosamine-2 epimerase active area that catalyzes the rate-limiting step in the sialic acid biosynthesis. Thus they can interfere with terminal glycosylation of proteins in the golgi apparatus [48].

It has been demonstrated that hydroxychloroquine blocks the M1 polarization which is the inflammatory macrophage subtype [63]. Eight to ten days after the symptoms start in COVID-19, conversion to the inflammatory M1 macrophage subtype occurrs against the humoral immune response to the SARSCoV-2S protein [48].

According to many studies; chloroquine and hydroxychloroquine improve glycemic control in treatment-resistant diabetic patients by repairing pancreatic $\beta$ function [64]. They provide the increase in insulin active form by inhibiting the enzymatic degradation of insulin via elevating the intracellular $\mathrm{pH}$. Besides reducing proinflammatory cytokines, especially TNF- $\alpha$ and IL-6, they reduce insulin resistance [60]. Therefore, in the COVID-19 patients who use antidiabetic medication, the dose adjustment of oral antidiabetic drugs or insulin should be done well while prescribing the chloroquine / hydroxychloroquine [8].

Data is limited for the use of chloroquine and hydroxychloroquine in COVID-19 and larger studies are needed. According to Chinese reports; chloroquine successfully treated 100 COVID-19 patients with improved radiological findings and increased viral clearance [65].

In the non-randomized 80 patients' clinical cohort, hydroxychloroquine and azithromycin combination reduced viral load in COVID-19 patients, and relieved clinical symptoms in most patients [66]. Moreover, in Wuhan, any of the 80 lupus patients receiving chronic hydroxychloroquine treatment have not been observed to develop COVID-19 infection. Subsequently, 62 patients with mild COVID-19 signs and symptoms were randomly treated with standard of care or $200 \mathrm{mg}$ hydroxychloroquine twice daily for 5 days alongside the standard of care. In $80.67 \%$ of the participants using hydroxychloroquine, COVID-19 pneumonia findings were repaired in CT scanning, in the control group, this rate remained at $50.8 \%$. While exacerbation of disease was not developed in any patient in the hydroxychloroquine group, in $12.9 \%$ of the control group patients, disease was aggravated [48, 67].

EC50 value of hydroxychloroquine was found lower compared to chloroquine [68]. Chloroquine dosage is $500 \mathrm{mg}$ orally 1 or 2 times a day [69]. According to pharmacokinetic modeling studies, for COVID-19 treatment, hydroxychloroquine should be used as $200 \mathrm{mg}$ twice a day, after the loading dose of $400 \mathrm{mg}$ twice a day [70].

Chloroquine and hydroxychloroquine are well tolerated drugs. But they can cause rare and serious side effects such as QTc prolongation, arrhythmia, hypoglycemia, neuropsychiatric effects, and retinopathy [70, 71]. Therefore, their use in high doses should be avoided [53].

\subsection{Antivirals}

Many antiviral drugs have been developed against viral proteases, polymerases and entry proteins. Most of them are being tested against SARS-CoV-2 in clinical trials [72].

\subsubsection{Interferon- $\alpha$}

Interferon- $\alpha$ which is the broad-spectrum antiviral agent is approved for viral hepatitis treatment. Interferon- $\alpha$ is used in the treatment of COVID-19 with vapor inhalation at a dosage of 5 million units twice a day. It is used for 10 days alone or combined with ribavirin (500 mg 2-3 times a day) or with lopinavir/ritonavir (400 mg/100 mg) [53]. 


\subsubsection{Interferon- $\beta$}

Interferon- $\beta$ has been developed to treat chronic obstructive pulmonary disease. It restores the lung damage and has the ability to fight the viral infection. The reduction in IFN- $\beta$ formation is related to the predisposition to the severe respiratory diseases as a result of viral infections. Immune system suppresses IFN$\beta$ formation in SARS-CoV-2 infection. In the UK, IFN- $\beta$ trial use has been approved in COVID-19 patients. Similar to IFN- $\alpha$; IFN- $\beta$ can be inhaled by self-administration of patients [53].

\subsubsection{Lopinavir/Ritonavir}

Lopinavir which is an antiretroviral agent that inhibits the protease enzyme. Lopinavir can be formulized with protease inhibitor ritonavir which decreases the metabolization of lopinavir by inhibiting cytochrome (CYT) P4503A enzyme. Lopinavir/ritonavir combination was approved for HIV treatment. It was also determined effective against SARS-CoV in the in vitro study [53]. It is applied in COVID-19 at a dose of $400 \mathrm{mg} / 100 \mathrm{mg}$ up to 14 days 2 times a day [73].

According to WHO current report, since this combination and hydroxychloroquine did not improve severe SARS-CoV-2 cases, WHO decided to conduct their clinical trials only in non-hospitalized patients or as pre- or post-exposure prophylaxis for COVID-19 [74].

\subsubsection{Ribavirin}

Ribavirin which is the guanin analogue inhibits the viral RNA dependent RNA polimerase. Its effects on other coronaviruses have suggested its use in the treatment of COVID-19. In the in vitro study, it was found that ribavirin inhibits SARS-CoV replication at high concentrations. It must be known that ribavirin leads to hematological toxicity in a dose dependent manner [70].

\subsubsection{Umifenovir (Arbidol)}

It is a promising antiviral agent that targets the $S$ protein / ACE2 interaction and has a unique mechanism of action that inhibits membrane fusion of the viral envelope [75]. It is an approved influenza drug in Russia and China. In vitro activity against SARS-CoV led to its use in COVID-19. It is being tried against COVID-19 with $200 \mathrm{mg}$ orally every 8 hours [70]. It is known to reduce mortality rates in COVID-19 patients [76].

\subsubsection{Remdesivir}

Remdesivir is a monophosphate prodrug which metabolizes to active C-adenosine nucleoside triphosphate analogue. Remdesivir is a viral replication inhibitor. It is effective on upper respiratory infection, especially at earlier phases. Remdesivir's RNA base adenosine-like structure provides the strong inhibition of viral RNA polymerase. Remdesivir is taken into RNA strands by the virus and causes chain termination [53]. The first clinical use of remdesivir has been in the treatment of Ebola [77]. Due to its broad spectrum, it is promising for the treatment of COVID-19. Remdesivir has shown in vitro activity against many coronaviruses, including SARS-CoV-2 [76]. Safety and pharmacokinetics of remdesivir have been investigated in single and multiple doses in phase 1 clinical trials. It was well tolerated in iv infusions between $3 \mathrm{mg}$ and $225 \mathrm{mg}$, liver and kidney toxicity did not develop. The treatment dose is $200 \mathrm{mg}$ single loading dose followed by $100 \mathrm{mg}$ daily infusion. Successful results have been reported in the treatment of COVID-19 [70].

\subsubsection{Favipiravir}

Favipiravir is the first agent approved for influenza virus in February 2020 [53]. It is an RNA dependent RNA polymerase inhibitor for the RNA viruses such as SARS-CoV-2. Favipiravir also has shown an effect against SARS-CoV-2 in vitro [78]. In February2020, favipiravir pre-clinical trials were conducted in 80 patients in China. Side effects were detected less compared to lopinavir / ritonavir [79]. Clinical researches are still in progress [70].

\subsection{Suppression of excessive inflammatory response}

Supression of excessive inflammatory response is thought of as the complementary treatment for the COVID-19 patients in the intensive care unit. But the therapeutic use of corticosteroids is controversial alongside their pharmacological positive effects [24]. The National Health Commission of the People's Republic of China (NHC) guidelines do not recommend routine use of systemic corticosteroids. In a recent 
retrospective study, the benefits of low-dose corticosteroids in patients with critical SARS-CoV-2 have been identified [80]. Studies are needed to determine how and when to use corticosteroids in COVID-19 cases.

Tocilizumab which is used in autoimmune diseases such as rheumatoid arthritis is an IL-6 antagonist. The multicentre, randomized, controlled clinical trial investigates the efficacy and safety of tocilizumab in COVID-19 patients. In Chinese clinical studies; tocilizumab has been shown to be effective in severe patients with extensive bilateral lung lesions with high IL-6 levels. The first dose is $4-8 \mathrm{mg} / \mathrm{kg}$. The recommended dosage is $400 \mathrm{mg}$ in $0.9 \%$ saline diluted to $100 \mathrm{~mL}$. Infusion time is more than 1 hour [24]. Sarilumab is also a human monoclonal antibody against the IL-6 receptor. Clinical research of sarilumab continues for COVID-19 infection. By blocking the IL-6 receptor, sarilumab is expected to reduce excessive inflammatory response of the lungs [53].

\subsection{Antimicrobial drugs for possible co-infection}

The prevalence of co-infection was determined to be 0-50\% among the COVID-19 patients who are nonsurvivors. Reported co-pathogens are bacteria (e.g., Mycoplasma pneumoniae Candida species) and viruses (e.g., influenza, rhinovirus, HIV). It is recommended to prescribe the antibacterial and antiviral drugs in cases of COVID-19 patients who should remain in the hospital for a long time [81].

\subsection{Recovered plasma}

Plasma of healed patients can be used to treat severe COVID-19 patients. Recovered plasma contains antibodies developed by the body in response to viral infection. Recovered plasma treatment was tried previously for SARS and good results were obtained [82].

Since the use of recovered plasma against COVID-19 has not yet been approved by the FDA, it is used as a research product. In clinical trials, this approach restored the clinical symptoms. But there is a risk for transmission of different diseases. Besides the amount of antibodies usually found is not sufficient for treatment. Studies to produce synthetic antibodies against COVID-19 continue [53].

\subsection{Statins}

Statins reinforce their beneficial effects in cardiovascular diseases by showing positive effects on inflammation and oxidative stress alongside of lipid-lowering activities. Statins affect different immune responses such as immune cell adhesion and migration, antigen presentation, cytokine formation. They repair vascular redox balance by reducing reactive oxygen species, increasing antioxidants and improving the nitric oxide bioavailability, endothelial function and integrity. Many of these effects are dependent on the downregulation of redox-sensitive proinflammatory transcriptional factors, such as nuclear factor kappa B (NF-kB) [83, 84].

SARS-CoV infection causes inflammation. Because hypoxia activates NF-kB and suppresses the Toll like receptor (TLR) which plays an important role in the immune system's recognition of foreign substances by triggering the myeloid differentiation primer response 88 (MYD88). Statins protects MYD88 at normal levels and reduces NF-KB activity during the hypoxia [85]. Animal studies have shown that in SARS-CoV and MERS$\mathrm{CoV}$ infections, suppression of the TLR pathway can increase the risk of viral loading and human-to-human transmission [86]. Therefore, some researchers have proposed to use statins in COVID-19 [87]. Although the clinical studies that demonstrate the protective effects of statins on COVID-19 are not available, they are known to be effective in mild pneumonia due to influenza [88].

COVID-19 has been reported to increase liver enzymes [89]. Statins can cause mild and temporary ALT and / or AST increase. Therefore, their use in COVID-19 cases should be followed.

As a result; the statins in use should be continued. If there are no contraindications, daily use of $40 \mathrm{mg}$ atorvastatin or $20 \mathrm{mg}$ rosuvastatin may be considered. If major drug-drug interactions with atorvastatin or rosuvastatin are present, $2 \mathrm{mg}$ pitavastatin or $80 \mathrm{mg}$ pravastatin may be considered daily [90].

\subsection{Treatment of COVID-19 in pregnancy}

To protect the placental perfusion and prevent the fetal hypoxia; high maternal oxygen and low carbon dioxide levels should be provided. Therefore, mechanical ventilation is applied in necessary cases [26]. World Health Organisation does not recommend the routine use of systemic corticosteroids because they delay viral clearance and do not have positive impact on survival [91]. Hydrocortisone and methylprednisolone do not pass through the placenta. On the other hand, prolonged exposure causes maternal hyperglycemia that is 
immunosuppressive and facilitate the replication of respiratory viruses in pulmonary epithelial cells. But in case of preterm labor, the decision to use corticosteroids should be made according to the patients' condition to accelerate fetal maturity and minimize peripartum complications. Good obstetric practice should be valid and urgent delivery should not be delayed [26].

Remdesivir is considered as safe to use in human pregnant women [26, 92]. Although chloroquine and its metabolites cross the placenta, it can be used safely in all trimesters of pregnancy. But chloroquine has a high volume of disruption [93]. Therefore, high doses should be used in pregnant COVID-19 cases (at least $500 \mathrm{mg} 2$ times day) [65].

Although lopinavir / ritonavir has not been specifically investigated for pregnancy, this combination is known to be safe. They did not increase the risk of fetal abnormalities, preterm birth, or low birth weight baby in HIV positive pregnants [94].

Ribavirin which is the guanosine analogue antiviral is teratogenic. Exposure of ribavirin at higher dose of $25 \mathrm{mg} / \mathrm{kg}$ has led to miscarriage, craniofacial and limb defects in embryos of pregnant mice [26].

\subsection{COVID-19 dependent neurological damage treatment}

Phenothiazine type antipsychotic chlorpromazine shows antiviral activity against many viruses and crosses the blood brain barrier. Chlorpromazine is estimated to be effective in preventing neurological damage in SARS-CoV-2. Ribavirin (nasal to brain administration) is another possible approach in neurological damage due to COVID-19. However, it should not be used in pregnant women since it is teratogenic. Since excessive inflammation and neuroimmune conditions play the important role in neurological damage in SARS-CoV-2; fingolimod which is used in multiple sclerosis, recombinant cytokines and interferons such as sarilumab and tocalizumab may also be preferred. Memantine and amantadine which are used for the treatment of Parkinson's disease, Alzheimer's disease and influenza have antiviral activity. Therefore, they can be effective for the prevention and treatment of viral replication in COVID-19-associated neuropathology [23].

\section{CONCLUSION}

Although SARS-CoV-2 virus causes milder cases in the general population compared to SARS-CoV and MERS-CoV; it is highly contagious and can cause fatal symptoms in the patients with underlying comorbidity and in older patients. Isolation of patients and asymptomatic carriers by testing as many people as possible has great importance in controlling COVID-19. In addition, until the vaccine and specific antiviral therapy against SARS-CoV-2 are developed; available treatment options are being tried to recover the COVID-19 cases with mild clinical symptoms.

Author contributions: Concept - Z.A.Ç.Y., G.Ş.; Design - Z.A.Ç.Y., G.Ş.; Supervision - Z.A.Ç.Y., S.Ş., G.Ş.; Data Collection and/or Processing - Z.A.Ç.Y., G.Ş.; Analysis and/or Interpretation -Z.A.Ç.Y., S.Ş., G.Ş.; Literature Search Z.A.Ç.Y., G.Ş.; Writing - Z.A.Ç.Y., G.Ş.; Critical Reviews - Z.A.Ç.Y., S.Ş., G.Ş.

Conflict of interest statement: The authors declared no conflict of interest.

\section{REFERENCES}

[1] WHO Summary of probably SARS cases with onset of illness from 1 November 2002 to 31 July 2003. http://www.who.int/csr/sars/country/table2004_04_21/en/ (accessed June 26, 2020).

[2] WHO SARS (Severe Acute Respiratory Syndrome). https://www.who.int/ith/diseases/sars/en/ (accessed July 10, 2020).

[3] WHO MERS Monthly Summary, November 2019. https://www.who.int/emergencies/mers-cov/en/ (accessed June 26, 2020).

[4] WHO Coronavirus disease pandemic situation reports. https://www.who.int/emergencies/diseases/novel-coronavirus-2019/situation-reports (accessed June 26, 2020).

[5] WHO Coronavirus disease (COVID-19) pandemic. https://www.who.int/emergencies/diseases/novelcoronavirus2019?gclid=Cj0KCQjwoub3BRC6ARIsABGhnybkbwRUe6DkDxC87G3rgSN5BqIaUVQK7ohEvvpH0Wily3NjUiNtd QgaApiuEALw_wcB (accessed July 01, 2020).

[6] Singh A, Shaikh A, Singh R, Singh AK. COVID-19: From bench to bed side. Diabetes Metab Syndr. 2020 ; 14: $277-281$. [CrossRef] 
[7] Lukassen S, Chua RL, Trefzer T, Khan NC, Schneider MA, Muley T, Winter H, Meister M, Veith C, Boots AW, Hennig BP, Kreuter M, Conrad C, Elis R. SARS-CoV-2 receptor ACE2 and TMPRSS2 are primarily expressed in bronchial transient secretory cells. EMBO J. 2020; 39(10): e105114. [CrossRef]

[8] Hussain A, Bhowmik B, do Vale Moreira NC. COVID-19 and Diabetes: Knowledge in Progress. Diabetes Res Clin Pract. 2020; 162: 108142. [CrossRef]

[9] Ortega JT, Serrano ML, Pujol FH, Rangel HR. Role of changes in SARS-CoV-2 spike protein in the interaction with the human ACE2 receptor: an in silico analysis. EXCLI J. 2020; 19: 410-417. [CrossRef]

[10] Hoffmann M, Keline-Weber H, Schroeder S, Krüger N, Herrler T, Erichsen S, Schiergens TS, Herrler G, Wu NH, Nitsche A, Müller MA, Drosten C, Pöhlman S. SARS-CoV-2 Cell Entry Depends on ACE2 and TMPRSS2 and Is Blocked by a Clinically Proven Protease Inhibitor. Cell. 2020; 181(2): 271-280. [CrossRef]

[11] Brojakowska A, Narula J, Shimony R, Bander J. Clinical Implications of SARS-CoV-2 Interaction With Renin Angiotensin System: JACC Review Topic of the Week. J Am Coll Cardiol. 2020; 75(24): 3085-3095. [CrossRef]

[12] Kreutz R, El_hady Algharably EA, Azizi M, Dobrowolski P, Guzik T, Januszewicz A, Persu A, Prejibsz A, Riemer TG, Wang JG, Burnier M. Hypertension, the renin-angiotensin system, and the risk of lower respiratory tract infections and lung injury: implications for COVID-19. Cardiovasc Res. 2020; 0: 1-12. [CrossRef]

[13] Walls AC, Park YJ, Tortorici MA, Wall A, McGuire AT, Veesier D. Structure, Function, and Antigenicity of the SARSCoV-2 Spike Glycoprotein. Cell. 2020; 181(2): 281-292.e6. [CrossRef]

[14] Zhang H, Penninger JM, Li Y, Zhong N, Slutsky AS. Angiotensin-converting enzyme 2 (ACE2) as a SARS-CoV-2 receptor: molecular mechanisms and potential therapeutic target. Intensive Care Med. 2020; 46: 586-590. [CrossRef]

[15] Haköksüz M, Kılıç S, Saraç F. Coronaviruses and SARS-COV-2. Turkish J Med Sci. 2020; 50: 459-456. [CrossRef]

[16] Shi J, Wen Z, Zhong G, Yang H, Wang C. Susceptibility of ferrets, cats, dogs, and different domestic animals to SARS coronavirus-2. Science. 2020; 368(6494): 1016-1020. [CrossRef]

[17] WHO Transmission of SARS-CoV-2: implications for infection prevention precautions. https://www.who.int/newsroom/commentaries/detail/transmission-of-sars-cov-2-implications-for-infection-prevention-precautions (accessed date July 17,2020)

[18] Shi H, Han X, Jiang N, Cao Y, Alwalid O, Gu J, Gu J, Fan Y, Zheng C. Radiological findings from 81 patients with COVID-19 pneumonia in Wuhan, China: a descriptive study. Lancet Infect Dis. 2020; 20(4): 425-34. [CrossRef]

[19] Zhao Y, Zhao Z, Wang Y, Zhou Y, Ma Y, Zuo W. Single-cell RNA expression profiling of ACE2, the putative receptor of Wuhan COVID-19. bioRxiv. 2020; 01.26.919985. [CrossRef]

[20] Acharya A, Kevadiya BD, Gendelman HE, Byrareddy SN. SARS-CoV-2 Infection Leads to Neurological Dysfunction. J Neuroimmune Pharm. 2020; 15: 167-173. [CrossRef]

[21] Li H, Xue Q, Xu X. Involvement of the Nervous System in SARS-CoV-2 Infection. Neurotox Res. 2020; 38(1): 1-7. [CrossRef]

[22] Duong L, Xu P, Liu A. Meningoencephalitis without respiratory failure in a young female patient with COVID-19 infection in downtown Los Angeles, early April 2020. Brain Behav Immun. 2020; 87: 33. [CrossRef]

[23] Singal CMS, Jaiswal P, Seth P. SARS-CoV-2 more than a respiratory virus: Its potential role in neuropathogenesis. ACS Chem Neurosci. 2020; 11(13): 1887-1899. [CrossRef]

[24] Ye Q, Wang B, Mao J. The pathogenesis and treatment of the 'Cytokine Storm' in COVID-19. J Infection. 2020; 80: 60713. [CrossRef]

[25] Chen L, Liu HG, Liu W, Liu J, Liu K, Shang J, Deng Y, Wei S. Analysis of clinical features of 29 patients with 2019 novel coronavirus pneumonia. Chin J Respir Dis. 2020; 43(0): E005. [CrossRef]

[26] Dashraath P, Wong JLJ, Lim MXK, Lim LM, Li S, Biswas A, Choolani M, Mattar C, Su LL. Coronavirus disease 2019 (COVID-19) pandemic and pregnancy. Am J Obstet Gynecol. 2020; 222(6): 521-531. [CrossRef]

[27] Chakrabotry C, Sharma AR, Sharma G, Bhattacharya M, Lee SS. SARS-CoV-2 causing pneumonia-associated respiratory disorder (COVID-19): diagnostic and proposed therapeutic options. Eur Rev Med Pharmacol Sci. 2020; 24(7): 4016-4026. [CrossRef]

[28] Song F, Shi n, Shan F, Zhang Z, Shen J, Lu H, Ling Y, Jiang Y, Shi Y. Emerging coronavirus 2019-nCoV pneumonia. Radiology. 2020; 295: 210-217. [CrossRef]

[29] Zhang P, Zhu L, Cai J, Lei F, Qin JJ, Xie J, Liu YM, Zhao YC, Huang X, Lin L, Xia M, Chen MM, Cheng X, Zhang X, Guo D, Peng Y, Ji YX, Chen J, She ZG, Wang Y, Xu Q, Tan R, Wang H, Lin J, Luo P, Fu S, Cai H, Ye P, Xiao B, Mao 
W, Liu L, Yan Y, Liu M, Chen M, Zhang XJ, Wang X, Touyz RM, Xia J, Zhang BH, Huang X, Yuan Y, Rohit L, Liu PP, $\mathrm{Li} \mathrm{H}$. Association of Inpatient Use of Angiotensin Converting Enzyme Inhibitors and Angiotensin II Receptor Blockers with Mortality Among Patients With Hypertension Hospitalized With COVID-19. Circ Res. 2020; 126(12): 1671-1681. [CrossRef]

[30] Rossi GP, Sanga V, Barton M. Potential Harmful Effects of Discontinuing ACE-Inhibitors and ARBs in Covid-19 Patients. Elife. 2020; 9: e57278. [CrossRef]

[31] Cure E, Cure MC. Angiotensin-converting enzyme inhibitors and angiotensin receptor blockers may be harmful in patients with diabetes during COVID-19 pandemic. Diabetes Metab Syndr. 2020; 14(4): 349-350. [CrossRef]

[32] Rico-Mesa JS, White A, Anderson AS. Outcomes in Patients with COVID-19 Infection Taking ACEI/ARB. Current Cardiology Reports. 2020; 22(5): 31. [CrossRef]

[33] Kai H, Kai M. Interactions of Coronaviruses With ACE2, Angiotensin II, and RAS Inhibitors-Lessons From Available Evidence and Insights Into COVID-19. Hypertens Res. 2020; 43(7): 648-654. [CrossRef]

[34] Kuba K, Imai Y, Rao S, Gao H, Guo F, Guan B, Huan Y, Yang P, Zhang Y, Deng W, Bao L, Zhang B, Liu G, Wang Z, Chappell M, Liu Y, Zheng D, Leibbrandt A, Wada T, Slutsky AS, Liu D, Qin C, Jiang C, Penninger JM. A crucial role of angiotensin converting enzyme 2 (ACE2) in SARS coronavirus-induced lung injury. Nat Med. 2005; 11(8): 875-879. [CrossRef]

[35] Imai Y, Kuba K, Rao S, Huan Y, Guo F, Guan B, Yang P, Sarao R, Wada T, Leong-Poi H, Crackower MA, Fukamizu A, Hui CC, Hein L, Uhlig S, Slutsky AS, Jiang C, Penninger JM. Angiotensin-converting enzyme 2 protects from severe acute lung failure. Nature. 2005; 436: 112-116. [CrossRef]

[36] Henry C, Zaizafoun M, Stock E, Ghamande S, Arroliga AC, White HD. Impact of angiotensin-converting enzyme inhibitors and statins on viral pneumonia. SAVE Proc. 2018; 31(4): 419e23. [CrossRef]

[37] Singh AK, Gupta R, Misra A. Comorbidities in COVID-19: Outcomes in hypertensive cohort and controversies with renin angiotensin system blockers. Diabetes Metab Syndr. 2020; 14: 283-287. [CrossRef]

[38] ESC Council on Hypertension Position statement of the ESC Council on hypertension on ACE-inhibitors and angiotensin receptor blockers. https://www.escardio.org/Councils/Council-on-Hypertension(CHT)/News/position-statement-of-the-esc-council-on-hypertension-on-ace-inhibitors-and-ang (accesed June 10, 2020).

[39] European Society of Hypertension, Statement of the European Society of Hypertension (ESH) on hypertension, renin angiotensin system blockers and COVID-19. https://www.eshonline.org/spotlights/esh-statement-on-covid-19/ (accessed June 10, 2020).

[40] Statement from the American Heart Association, the Heart Failure Society of America, and the American College of Cardiology. Patients taking ACE-i and ARBs who contract COVID-19 should continue treatment, unless otherwise advised by their physician. https://newsroom.heart.org/news/patients-taking-ace-i-and-arbs-who-contract-covid19-should-continue-treatment-unlessotherwise-advised-by-their-physician (accessed June 10, 2020).

[41] Ma RCW, Holt RIG. COVID-19 and diabetes. Diabet Med. 2020; 00: 1-3. [CrossRef]

[42] Kohio Hinissan P, Adamson Amy L. Glycolytic control of vacuolar-type ATPase activity: a mechanism to regulate influenza viral infection. Virology. 2013; 444(1-2): 301-309. [CrossRef]

[43] Roca-Ho H, Riera M, Palau V, Pascual J, Soler MJ. Characterization of ACE and ACE2 Expression within Different Organs of the NOD Mouse. Int J Mol Sci. 2017; 18(3): 563. [CrossRef]

[44] Singh AK, Gupta R, Ghosh A, Misra A. Diabetes in COVID-19: Prevalance, pathophysiology, prognosis and practical considerations. Diabetes Metab Syndr. 2020; 14: 303-310. [CrossRef]

[45] Fernandez C, Rysa J, Almgren P, Nilsson J, Engström G, Orho-Melander M, Ruskoaho H, Melander O. Plasma levels of the proprotein convertase furin and incidence of diabetes and mortality. J Intern Med. 2018; 284(4): 377-87. [CrossRef]

[46] Wu Z, McGoogan JM. Characteristics of and important lessons from the coronavirus disease 2019 (COVID-19) outbreak in China: summary of a report of 72314 cases from the Chinese center for disease control and prevention. J Am Med Assoc. 2020; 323(13): 1239-1242. [CrossRef]

[47] Guan WJ, Ni ZY, Hu Y, Liang WH, Ou CQ, He JX, Liu L, Shan H, Lei CL, Hui DSC, Du B, Li LJ, Zeng G, Yuen KY, Chen RC, Tang CL, Wang T, Chen PY, Xiang J, Li SY, Wang JL, Liang ZJ, Peng YX, Wei L, Liu Y, Hu YH, Peng P, Wang JM, Liu JY, Chen Z, Li G, Zheng ZJ, Qiu SQ, Luo J, Ye CJ, Zhu SY, Zhong NS and for the China Medical Treatment Expert Group for Covid-19. Clinical Characteristics of Coronavirus Disease 2019 in China. N Engl J Med. 2020; 382(18): 1708-1720. [CrossRef] 
[48] Brufsky A. Hyperglycemia, Hydroxychloroquine, and the COVID-19 Epidemic. J Med Virol. 2020; 92: 770-775. [CrossRef]

[49] Wang F, Wang H, Fan J, Zhang Y, Wang H, Zhao Q. Pancreatic injury patterns in patients with COVID-19 pneumonia. Gastroenterology. 2020; 159(1): 367-370. [CrossRef]

[50] Drucker DJ. Coronavirus infections and type 2 diabetes-shared pathways with therapeutic implications. Endocr Rev. 2020; 41(3): bnaa011. [CrossRef]

[51] Russell CD, Millar JE, Baillie JK. Clinical evidence does not support corticosteroid treatment for 2019-nCoV lung injury. Lancet. 2020; 395(10223): 473-475. [CrossRef]

[52] Zhou J, Tan J. Diabetes patients with COVID-19 need better Blood Glucose Management in Wuhan, China. Metabolism. 2020; 107: 154216. [CrossRef]

[53] Ahsan W, JAved S, Al Bratty M, Alhazmi HA, Najmi A. Treatment of SARS-CoV-2: How far have we reached? Drug Discov Ther. 2020; 14(2): 67-72. [CrossRef]

[54] Yu L, Yuan K, Phuong HT, Park BM, Kim SH. Angiotensin-(1-5), an active mediator of renin-angiotensin system, stimulates ANP secretion via Mas receptor. Peptides. 2016; 86: 33-41. [CrossRef]

[55] Battle D, Wysocki J, Satchell K. Soluble angiotensin-converting enzyme 2: a potential approach for coronavirus infection therapy? Clin Sci (Lond). 2020; 134 (5): 543-545. [CrossRef]

[56] Lei C, Fu W, Qian K, Li T, Zhang S, Ding M, Hu S. Potent neutralization of 2019 novel coronavirus by recombinant ace2-ig. BioRxiv. 2020. [CrossRef]

[57] Zhang F, Liu J, Li SF, Song JX, Ren JY, Chen H. Angiotensin-(1-7): new perspectives in atherosclerosis treatment. J Geriatr Cardiol. 2015; 12: 676-682. [CrossRef]

[58] Padda RS, Shi Y, Lo CS, Zhang SL, Chan J. Angiotensin-(1-7): A Novel Peptide to Treat Hypertension and Nephropathy in Diabetes? J Diabetes Metab. 2015; 6(10): 10.4172/2155-6156.1000615. [CrossRef]

[59] Perio C, Moncada S. Substituting Angiotensin-(1-7) to Prevent Lung Damage in SARS-CoV-2 Infection? Circulation. 2020; 141: 1665-1666. [CrossRef]

[60] Pal R, Phadada SK. Should anti-diabetic medications be reconsidered amid COVID-19 pandemic? Diabetes Res Clin Pract. 2020; 163: 108146. [CrossRef]

[61] Gendrot M, Javelle E, Clerc A, Savini H, Pradines B. Chloroquine as a prophylactic agent against COVID-19? Int J Antimicrob Agents. 2020; 55(6): 105980. [CrossRef]

[62] Wang M, Cao R, Zhang L, Yang X, Liu J, Xu M, Shi Z, Hu Z, Zhong W, Xiao G. Remdesivir and chloroquine effectively inhibit the recently emerged novel coronavirus (2019-nCoV) in vitro. Cell Res. 2020; 30(3): 269-71. [CrossRef]

[63] Shiratori H, Feinweber C, Luckhardt S, Wallner N, Geisslinger G, Weigert A, Parnham MJ. An in vitro test system for compounds that modulate human inflammatory macrophage polarization. Eur J Pharmacol. 2018; 833: 328-338. [CrossRef]

[64] Rekedal LR, Massarotti E, Garg R, Bhatia R, Gleeson T, Lu B, Solomon DH. Changes in glycosylated hemoglobin after initiation of hydroxychloroquine or methotrexate treatment in diabetes patients with rheumatic diseases. Arthritis Rheum. 2010; 62(12): 3569-3573. [CrossRef]

[65] Gao J, Tian Z,Yang X.Breakthrough: chloroquine phosphate has shown apparent efficacy in treatment of COVID-19 associated pneumonia in clinical studies. BiosciTrends. 2020; 14(1): 72-73. [CrossRef]

[66] Gautret P, Lagier J-C, Parola P, Hoang VT, Meddeb L, Mailhe M, Doudier B, Courjon J, Giodanengo V, Vieira VE, Dupont HT, Honore S, Colson P, Chabriere E, La Scola B, Rolain JM, Brouqui P, Raoult D. Hydroxychloroquine and azithromycin as a treatment of COVID-19: results of an open-label non-randomized clinical trial. Int J Antimicrob Agents. 2020; 105949. [CrossRef]

[67] Chen Z, Hu J, Zhang Z, Jiang S, Han S, Yan D, Zhuang R, Hu B, Zhang Z. Efficacy of hydroxychloroquine in patients with COVID-19: results of a randomized clinical trial. medRxiv. 2020. [CrossRef]

[68] Yao X, Ye F, Zhang M, Cui C, Huang B, Niu P, Liu X, Zhao L, Dong E, Song C, Zhan S, Lu R, Li H, Tan W, Liu D. In vitro antiviral activity and projection of optimized dosing design of hydroxychloroquine for the treatment of severe acute respiratory syndrome coronavirus2 (SARS-CoV-2). Clin Infect Dis. 2020; 71(15): 732-739. [CrossRef]

[69] Colson P, Rolain JM,Lagier JC,Brouqui P, Raoult D. Chloroquine and hydroxychloroquine as available weapons to fight COVID-19. Int J Antimicrob Agents. 2020; 55(4): 105932. [CrossRef] 
[70] Sanders JM, Monogue ML, Jodlowski TZ, Cutrell JB. Pharmacologic Treatments for Coronavirus Disease 2019 (COVID-19) A Review. JAMA. 2020; 323(18): 1824-1836. [CrossRef]

[71] Kalil AC. Treating COVID-19-off-labe ldrug use, compassionate use,and randomized clinical trials during pandemics. JAMA. 2020; 323(19): 1897-1898. [CrossRef]

[72] Li H, Zhou Y, Zhang M, Wang H, Zhao Q, Liu J. Updated Approaches against SARS-CoV-2. Antimicrob Agents Chemother. 2020; 64: e00483-20. [CrossRef]

[73] National Health Commission and State Administration of Traditional Chinese Medicine. Diagnosis and treatment protocol for novel coronavirus pneumonia. Chin Med J. 2020; 133: 1087-1095. [CrossRef]

[74] WHO discontinues hydroxychloroquine and lopinavir/ritonavir treatment arms for COVID-19. https://www.who.int/news-room/detail/04-07-2020-who-discontinues-hydroxychloroquine-and-lopinavirritonavir-treatment-arms-for-covid-19 (accessed June 27, 2020).

[75] Kadam RU, Wilson IA. Structural basis of influenza virus fusion inhibition by the antiviral drug Arbidol. Proc Natl Acad SciUSA. 2017; 114(2): 206-214. [CrossRef]

[76] Wang Z, Yang B, Li Q, Wen L, Zhang R. Clinical Features of 69 cases with coronavirus disease 2019 in Wuhan, China. Clin Infect Dis. 2020; 71(15): 769-777. [CrossRef]

[77] Jacobs M, Rodger A, Bell DJ, Bhagani S, Cropley L, Filipe A, Gifford RJ, Hopkins S, Hughes J, Jabeen F, Johannessen I, Karageorgopoulos D, Lackenby A, Lester R, Liu RSN, MacConnachie A, Mahungu T, Martin D, Marshall N, Mepham S, Orton R, PAlmarini M, Patel M, Perry C, Peters SE, Porter D, Ritchie Di Ritchie ND, Seaton RA, Sreenu VB, Templeton K, Warren S, Wilkie GS, Zambon M, Gopal R, Thomson EC. Late Ebola virus relapse causing meningo encephalitis:a case report. Lancet. 2016; 388(10043): 498-503. [CrossRef]

[78] Wang M, Cao R, Zhang L, Yang X, Liu J, Xu M, Shi Z, Hu Z, Zhong W, Xiao G. Remdesivir and chloroquine effectively inhibit the recently emerged novel coronavirus (2019-nCoV) in vitro. Cell Res. 2020; 30(3): 269-271. [CrossRef]

[79] Cai Q, Yang M, Liu D. Experimental treatment with favipiravir for COVID-19: An open-label control study. Engineering. 2020. [CrossRef]

[80] Zhou W, Liu Y, Tian D, Wang C, Wang S, Cheng J, Hu M, Fang M, Gao Y. Potential benefits of precise corticosteroids therapy for severe 2019-nCoV pneumonia. Signal Transduct Target Ther. 2020; 5: 18. [CrossRef]

[81] Jean SS, Lee PI, Hsueh PR. Treatment options for COVID-19: The reality and challenges. J Microbiol Immunol Infect. 2020; 53: 436-443. [CrossRef]

[82] Chen L, Xiong J, Bao L, Shi Y. Convalescent plasma as a potential therapy for COVID-19. Lancet Infect Dis. 2020; 20: 398-400. [CrossRef]

[83] Zeiser R. Immune modulatory effects of statins. Immunology. 2018; 154: 69-75. [CrossRef]

[84] Castiglione V, Chiriaco M, Emdin M, Taddei S, Vergaro G. Statin therapy in COVID-19 infection. Eur Heart J Cardiovasc Pharmacother. 2020; 6(4): 258-259. [CrossRef]

[85] Chansrichavala P, Chantharaksri U, Sritara P, Chaiyaroj SC. Atorvastatin attenuates TLR-4mediated NF-kappa B activation in a MyD88-dependent pathway. Asian Pac J Allergy Immunol. 2009; 27: 49-57.

[86] Totura AL, Whitmore A, Agnlhram S, Schäfer A, Katze MG, Heise MT, Baric RS. Toll-like receptor 3 signaling via TRIF contributes to a protective innate immune response to severe acute respiratory syndrome coronavirus infection. mBio. 2015; 6(3): e00638-15. [CrossRef]

[87] Fedson DS, Opal SM, Rordam OM. Hiding in plain sight: an approach to treating patients with severe COVID-19 infection. mBio. 2020; 11(2): e00398-20. [CrossRef]

[88] Frost FJ, Petersen H, Tollestrup K, Skipper B. Influenza and COPD mortality protection as pleiotropic, dosedependent effects of statins. Chest. 2007; 131(4): 1006-1012. [CrossRef]

[89] Xu L, Liu J, Lu M, Yang D, Zheng X. Liver injury during highly pathogenic human coronavirus infections. Liver Int. 2020; 40(5): 998-1004. [CrossRef]

[90] Massacheusetts General Hospital Rationale for Consideration of Statins for COVID-19 Patients. https://www.massgeneral.org/assets/MGH/pdf/news/coronavirus/covid-19_domID_statin.pdf (accessed July, 02 2020)

[91] WHO Novel coronavirus technical guidance: patient management. https://www.who.int/emergencies/diseases/novel-coronavirus2019/technical-guidance/patient-management (accessed February 20, 2020). 
[92] Mulangu S, Dodd LE, Davey RT Jr, Mbaya OT, Proschan M, Mukadi D, Manzo ML, Nzolo D, Oloma AT, Ibanda A, Ali R, Coulibaly S, Levine AC, Grais R, Diaz J, Lane HC, Muyembe-Tamfum JJ and for the PALM Consortium Study Team. A randomized, controlled trial of Ebola virus disease therapeutics. N Engl J Med. 2019; 381: $2293-303$. [CrossRef]

[93] Karunajeewa HA, Salman S, Mueller I, Baiwog F, Gomorrai S, Law I, Pag-Sharp M, Rogerson S, Siba P, Ilett KF, Davis TME. Pharmacokinetics of chloroquine and monodesethylchloroquine in pregnancy. Antimicrob Agents Chemother. 2010; 54: 1186-1192. [CrossRef]

[94] Tookey PA,Thorne C,van Wyk J, Norton M. Maternal and foetal outcomes among 4118 women with HIV infection treated with lopinavir/ ritonavir during pregnancy: analysis of population-based surveillance data from the national study of HIV in pregnancy and childhood in the United Kingdom and Ireland. BMC Infect Dis. 2016; 16: 65-75. [CrossRef]

This is an open access article which is publicly available on our journal's website under Institutional Repository at http://dspace.marmara.edu.tr. 